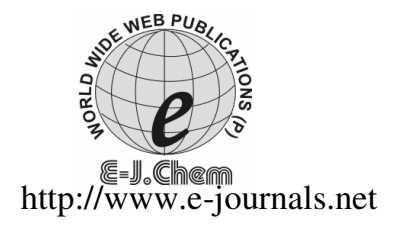

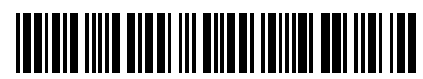

ISSN: 0973-4945; CODEN ECJHAO

E-Journal of Chemistry

2011, 8(3), 1444-1450

\title{
HPTLC Method Development and Validation for Determination of Rutin in Flavanoidal Fraction of Hibiscus Micranthus Linn.
}

\author{
K. ASHOK KUMAR ${ }^{*}$, S. RAMACHANDRA SHETTY ${ }^{\S}$ and LAXMI NARSU, \\ *Department of Pharmacognosy, Bharat Institute of Technology Pharmacy \\ Ibrahimpatnam, RR Dist-510501, India \\ ${ }^{\S}$ Department of Pharmacology, College of Clinical Pharmacy \\ King Faisal University, Alahsa-31982, India \\ Department of Biotechnology, Jawaharlal Nehru Technological University \\ Kukattpally, Hyderabad. 517132, Andhra Pradesh, India \\ kurashok2000@yahoomail.com
}

Received 24 March 2010; Accepted 30 May 2010

\begin{abstract}
A simple, precise and accurate high-performance thin-layer chromatographic method has been established for the determination of rutin in the stem extract of Hibiscus micranthus Linn. A flavonoid fraction of methanolic extract of the stem powder was used for the experimental work. Separation was performed on silica gel $60 \mathrm{~F}_{254}$ HPTLC plates with $n$-butanol: acetic acid: water: ammonia $3: 1: 1: 1(\mathrm{v} / \mathrm{v})$, as mobile phase. The determination was carried out using the densitometric absorbance mode at $286 \mathrm{~nm}$. Rutin response was linear over the range $50-400 \mathrm{ng} / \mu \mathrm{L}$. The concentration of rutin in the flavanoidal fraction was found to be $9.93 \%$. The HPTLC method was evaluated in terms of sensitivity, accuracy, precision and reproducibility.
\end{abstract}

Keywords: Flavanoidal fraction, Rutin, Hibiscus micranthus, HPTLC, Method validation

\section{Introduction}

Hibiscus micranthus Linn. (malvaceae) is a shrubby, erect, branched, slender and stellately hairy plant. It is widely distributed in hotter parts of India, Ceylon, Saudi Arabia and tropical Africa. In India, the plant is known by different vernacular names in different regions as chalabharate in telugu, sittamutti in tamil, chanakbhindo in gujrati and as okder in sanskrit. Traditionally the plant is considered a valuable febrifuge in India, Ceylon, Saudi Arabia and tropical Africa ${ }^{1}$. In India certain parts of Gujarat, the fruits and flowers of this plant is used as hypoglycemic agent ${ }^{2}$. The plant has been scientifically validated for its antipyretic, 
anti-inflammatory, hematological effects ${ }^{3}$, antimicrobial, antiviral, antitumor ${ }^{4}$, female antifertility, viralizing ${ }^{5}$ and anabolizing ${ }^{6}$ activities. Few compounds like phenolic acids, flavonoids, $\beta$-sitosterol, alkanes, fatty alcohols and acids have been reported on carrying out conventional column chromatographic analysis. Rutin has been reported to have antidiabetic, anti-thrombotic, anti-inflammatory and anti-carcinogenic activity ${ }^{7}$. The literature survey revealed that determination of rutin in flavanoidal fraction of stem extract of Hibiscus micranthus (FFHM). By HPTLC is not reported. However, references are available for the determination of rutin from a mixture or plant extracts ${ }^{8-13}$. The objective of the present work is to develop a simple, economical, precise and accurate HPTLC method for the determination of rutin in FFHM.

\section{Experimental}

The whole plant material were collected in and around the campus of Bharat Institute of Technology Pharmacy, Mangalpally, Ibrahimpatnam and were authenticated by Taxonomist Dr. Jayaraman at the National Institute of Herbal science, Chennai, India. In order to ensure the sample used was from the same source throughout the experiment, the sample was collected in sufficient quantities at a time. The plant Hibiscus micranthus Linn., was washed thoroughly with running tap water, followed by rinsing with distilled water and then leaves, stem and roots were separated and cut into small pieces. The stems were shade dried at room temperature for four weeks. The dried stems were powdered in mill to a mesh size of 80 and stored in a air tight container till further use. All the solvents were of analytical grade from SD fine chemicals. Standard rutin (95\% pure) was procured from Loba Chemie (mumbai, India). Silica gel $60 \mathrm{~F}_{254}$ HPTLC precoated plates were procured from Merck (Darmstadt, Germany).

\section{Preparation of standard stock solution}

A stock solution of rutin $(1000 \mu \mathrm{g} / \mathrm{mL})$ was prepared by dissolving $25 \mathrm{mg}$ of accurately weighed rutin in methanol and diluting to $25 \mathrm{~mL}$ with methanol in a standard volumetric flask. A series of working standard solutions of concentrations 50, 100, 150, 200, 250, 300, 350 and $400 \mathrm{ng} / \mu \mathrm{L}$ were prepared by the dilution of aliquots $0.5-4 \mathrm{~mL}$ of stock solution in a $10 \mathrm{~mL}$ standard volumetric flask with methanol.

\section{Sample preparation}

Flavanoidal fraction from stems of Hibiscus micranthus Linn. was separated as per the procedure followed by Jain $e t a l^{7} .25 \mathrm{mg}$ of FFHM was placed in a stoppered tube and to this $25 \mathrm{~mL}$ of methanol were added. The sample was vortex mixed for $2 \mathrm{~min}$ and left to stand overnight at room temperature $\left(28 \pm 2{ }^{\circ} \mathrm{C}\right)$. The contents of the tube were then filtered through a Whatman No.41 paper (E. Merck, Mumbai, India) and the clear supernatant solution was used for the assay.

\section{Linearity of detector response}

Standard rutin solutions of different concentrations (50, 100, 150, 200, 250, 300, 350 and $400 \mathrm{ng} / \mu \mathrm{L}$ ) were prepared in methanol. The determination experiment was on silica gel $60 \mathrm{~F}_{254}$ HPTLC plates (Merck) using mobile phase $n$-butanol: acetic acid: water: ammonia 3:1:1:1(v/v). $10 \mu \mathrm{L}$ of standard solutions was applied to the plate as $7 \mathrm{~mm}$ bands at a distance of $15 \mathrm{~mm}$ from the edge of the plate with the help of Camag Linomat IV sample applicator. The plate was developed to a distance of $8 \mathrm{~cm}$ in a Camag twin trough chamber previously equilibrated with the mobile phase (45 min). The developed HPTLC plate was dried using a 
dryer for 2 min and then scanned between 200 and $400 \mathrm{~nm}$, with a Camag Scanner II having a deuterium lamp in conjunction with Cats 3 version software. The wavelength of $286 \mathrm{~nm}$ was used for quantitation. A linear relationship between the peak areas and concentrations was observed for rutin in the concentration range of 50-400 $\mathrm{ng} / \mu \mathrm{L}$. The same exercise was repeated thrice and the mean was used for calculation. The data obtained is presented in Table 1. Calibration curve of standard rutin trihydrate is presented in Figure 1.

Table 1. Linear regression data for the calibration curve $(n=6)$

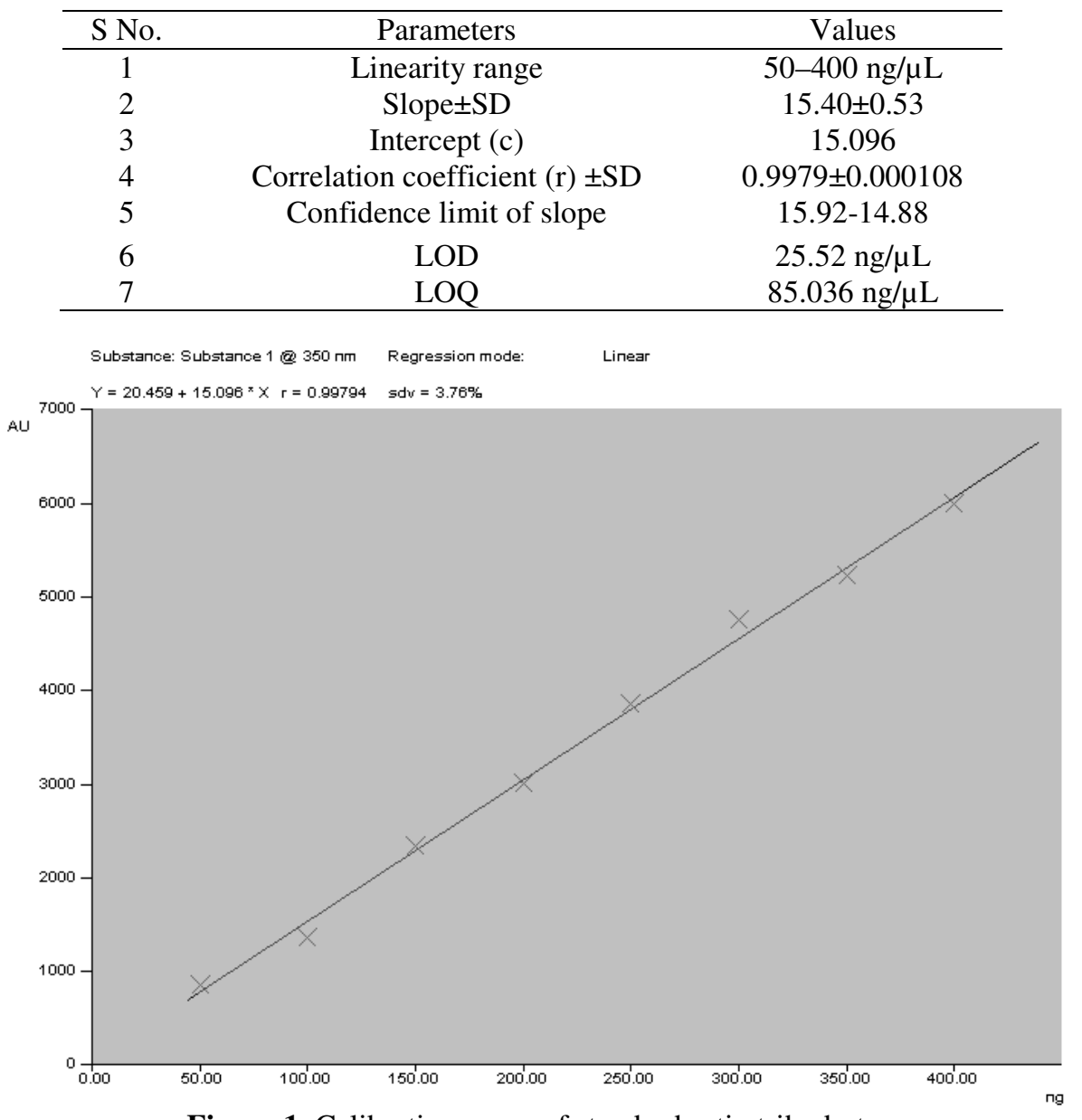

Figure 1. Calibration curve of standard rutin trihydrate

Assay

$10 \mu \mathrm{L}$ of the standard solution of rutin $(350 \mathrm{ng} / \mu \mathrm{L})$ and plant extract were applied to the chromatographic plate, the plate was developed and the peak areas of rutin were measured. The amount of rutin present in sample solution was then determined using linearity equation. The procedure so described for the assay was repeated seven times, starting right from the weighing of the FFHM. The mean assay value of rutin was found to be $0.32 \mu \mathrm{g}$. The overlay of UV spectrum of standard rutin and rutin in FFHM is shown in Figure 3. The HPTLC chromatograms of standard rutin and FFHMM are shown in Figure 4. 


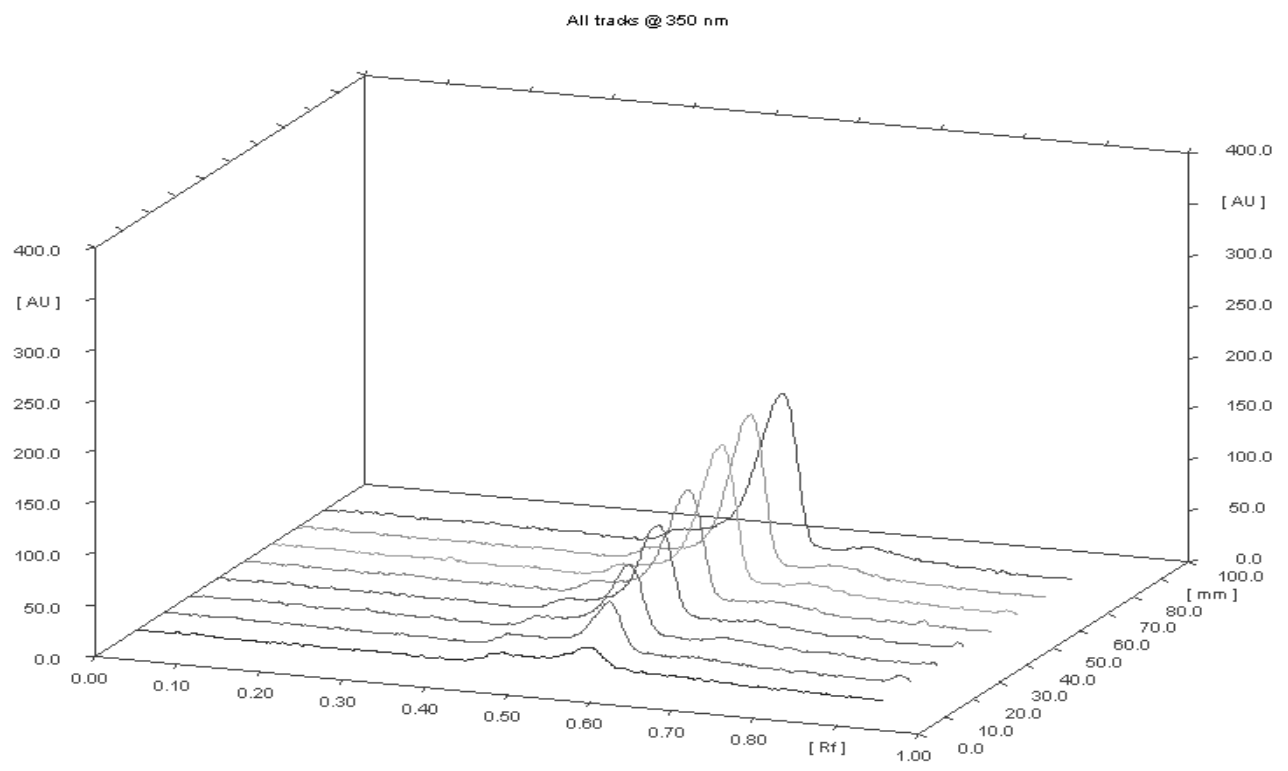

Figure 2. Dimensional HPTLC chromatogram of standard rutin trihydrate Spectra comparison

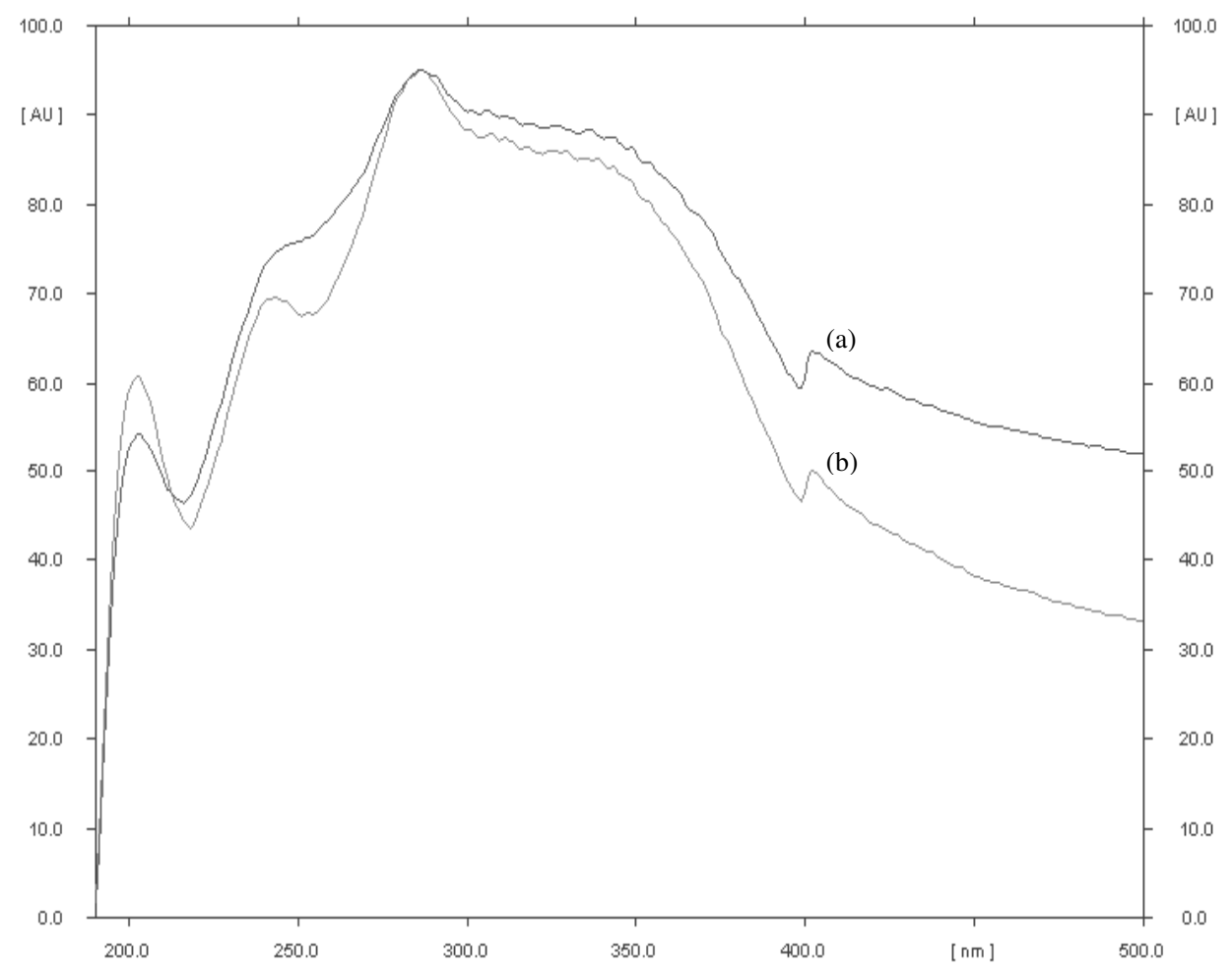

Figure 3. Online UV spectra of rutin in std; a) $\lambda_{\max }=286 \mathrm{~nm}$ and rutin in FFHM; b) $\lambda_{\max }$ $=285 \mathrm{~nm}$ 


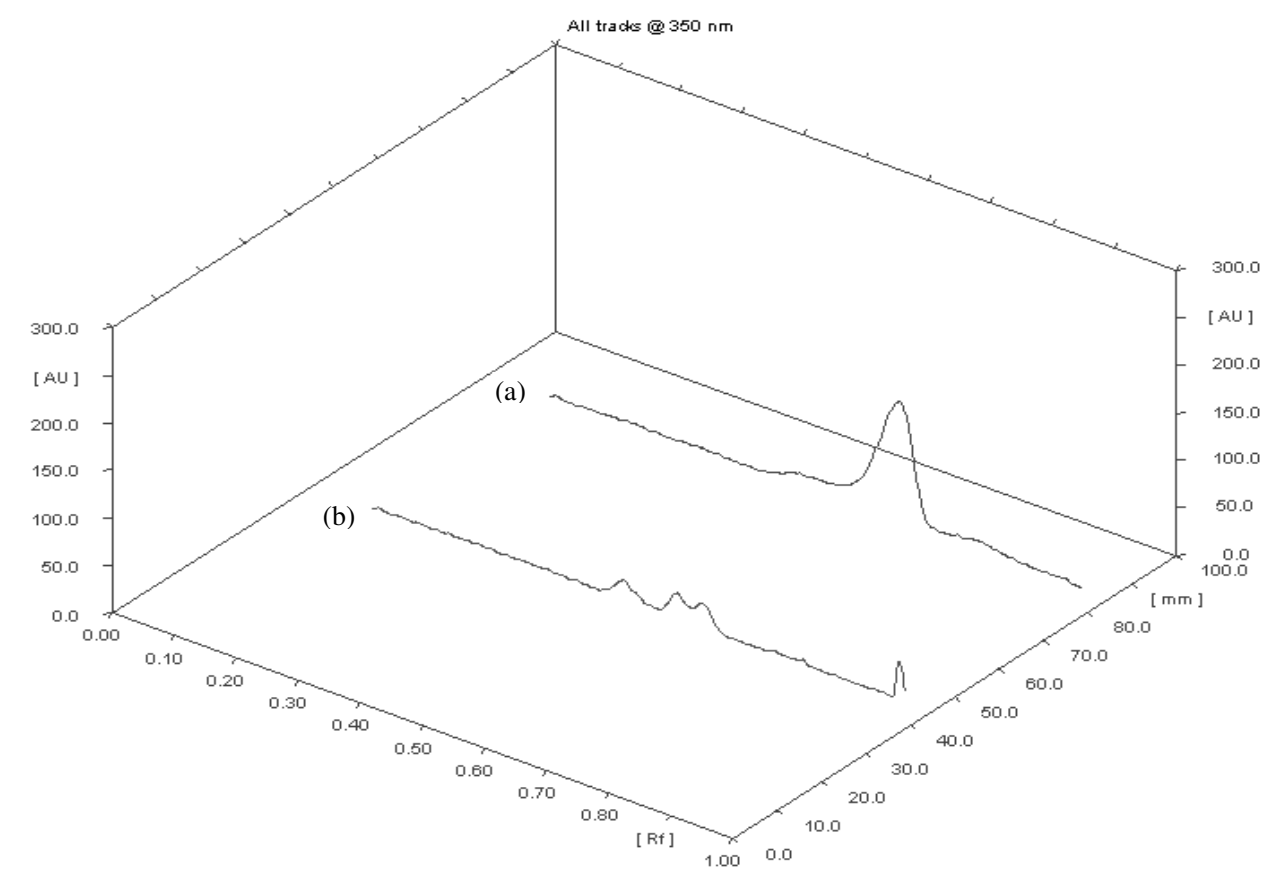

Figure 4. A typical HPTLC chromatogram of standard rutin and plant; a) standard rutin, b) FFHM.

\section{Validation}

\section{Precision and accuracy}

The method was validated for precision and accuracy. Precision was checked by scanning the same rutin spot $(200 \mathrm{ng} / \mu \mathrm{L}, \mathrm{n}=6)$ and was expressed as standard deviation (\%SD). Accuracy of the method was studied by recovery experiment by the method of standard addition. Standard rutin solutions were added to the FFHM and the percent recovery was determined at three different levels, each determined in a manner similar to that described for the assay. The rutin content was determined by the proposed method as described earlier and the percent recovery was calculated. The results of the recovery analysis are given in Table 2.

Table 2. Precision and accuracy of the method applied to spiked rutin samples

\begin{tabular}{cccc}
\hline $\begin{array}{c}\text { Amount } \\
\text { added, ng/ } \mu \mathrm{L}\end{array}$ & $\begin{array}{c}\text { Amount found, } \\
\mathrm{ng} / \mu \mathrm{L}\end{array}$ & $\begin{array}{c}\text { Precision/Reproducibility (C.V) } \\
(\text { Mean } \pm \text { S.D n=6) }\end{array}$ & $\begin{array}{c}\text { Mean recovery, } \\
\%\end{array}$ \\
\hline 100 & $94.10 \pm 1.43$ & 1.521 & 94.10 \\
150 & $144.7 \pm 1.73$ & 1.196 & 96.51 \\
200 & $194.0 \pm 1.11$ & 0.574 & 97.01 \\
\hline
\end{tabular}

\section{Ruggedness and robustness}

Ruggedness of the method was carried out by two different analyst and results are represented in terms of (\%RSD) Table 3. Robustness of the method was conducted by changing the composition of mobile phase and developmental distance of $9.0 \mathrm{~cm}$ and $8.5 \mathrm{~cm}$. The results are shown in Table 4 in terms of (\%RSD). 
Table 3. Ruggedness of the method $(n=6)$

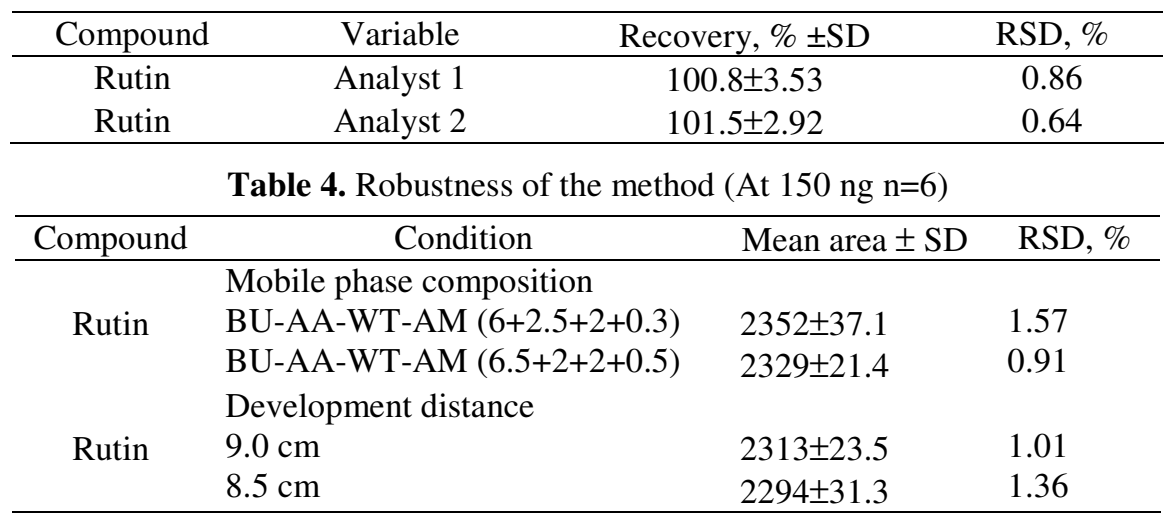

BU-AA-WT-AM--N-butanol-Acetic acid-Water-Ammonia

\section{Results and Discussion}

The method developed is a normal phase HPTLC method. Silica gel $60 \mathrm{~F}_{254}$ stationary phase precoated on aluminum sheet was used for the analysis. The mobile phase comprised n-butanol: acetic acid: distilled water: ammonia in the proportion $3: 1: 1: 1(\mathrm{v} / \mathrm{v})$, which gave good separation of rutin $(\mathrm{RF}=0.55)$ from the other phytochemicals of FFHM. The identity of rutin in the FFHM was confirmed by overlaying the spectrum chromatogram of rutin in FFHM with that of the rutin standard both obtained with the Camag TLC Scanner. The detector response of rutin was found to be linear in the range $50-400 \mathrm{ng} / \mu \mathrm{L}$ with correlation coefficient of $0.9979 \pm 0.000108$. The concentration of rutin in the FFHM was found to be $9.93 \%$.

Instrument precision was measured to evaluate the precision of the method. SD was found to be $<2 \%$ which indicates that the developed method is highly precise and reproducible. The percent recovery of 97.01 indicates the accuracy of the proposed method. The ruggedness of the method was studied, using two analyst and \%RSD was found to be $<1 \%$. Robustness of the method was studied, during method development, by determining the effects of small variation, of mobile phase composition and development distance $( \pm 2 \%)$. No significant change of RF or response to rutin was observed, indicating the robustness of the method.

The proposed method is specific for determination of rutin from flavanoidal fraction, the pattern produced will be characteristic of Hibiscus micranthus Linn. and can be readily profiled.

\section{Conclusion}

The proposed method is simple, precise, accurate and sensitive and can be used for-routine quality-control of Hibiscus micranthus Linn.

\section{References}

1. Kirtikar K R and Basu B D, In Indian Medicinal Plants, Periodical Expert Book Agency. Delhi, $2^{\text {nd }}$ Edn., 1984, 1, 293.

2. Kakrani H N, Bhanu H Kakrani and Ajay K Saluja, Planta Indica, 2005, 1(1), 16-21. 
3. Al-yahya M A, Tariq M, Parmar N S and Ageel A M, Phytotherapy Res., 1987, 1(2), 73-75.

4. Jain R, Arora R and Jain S C, Indian J Pharm Sci., 1997, 3, 91-93.

5. Telefro P B, Moundipa P F, Tehana A N C, Tchouanguep C D and Mbiapo F T, $J$ Ethnopharmacol., 1998, 63, 193-200.

6. Moundipa F P, Kamtchouing P, Koueta N, Tantchou J, Foyang N P and Mbiapo F T, J Ethnopharmacol, 1999, 65, 133-139.

7. Stinzinga F C, Kammerera D, Schiebera A, Adamab H, Nacoulmab O G and Carlea R, Z Naturforsch C Biosci., 2004, 59, 1-8.

8. Olajide O A, Ogunleye B R and Erinle T O, Pharm Biol., 2004, 42(7), 521-525.

9. Gupta A K and Tandon N, Reviews on Indian Medicinal Plants, ICMR, Delhi, 2004, 2, 70-190.

10. Rastogi R P and Mehrotra B N, Compendium of Indian Medicinal Plants, CDRI \& NISCAIR, Lucknow, 1999, 2, 38.

11. Srinivasan K, Kaul C L and Ramarao P, Indian J Pharmacol., 2005, 37(5), 327-328.

12. Kumar V P, Ravishankara M N, Padh H and Rajani M, J Planar Chromatogr., 2003 16(5), 386-389.

13. Swaroop A, Gupta A P and Sinha A K, Chromatogr., 2005, 62(11-12), 649-652. 


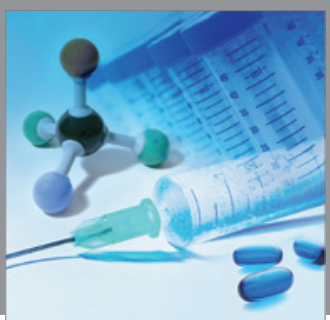

International Journal of

Medicinal Chemistry

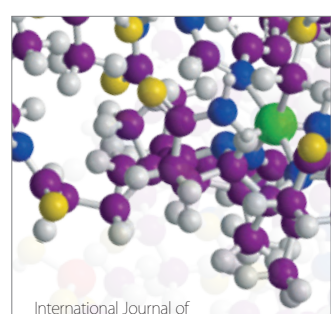

Carbohydrate Chemistry

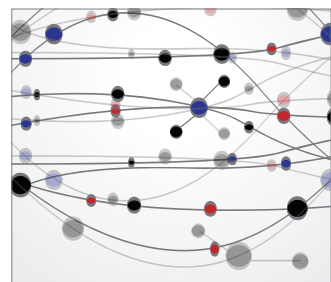

The Scientific World Journal
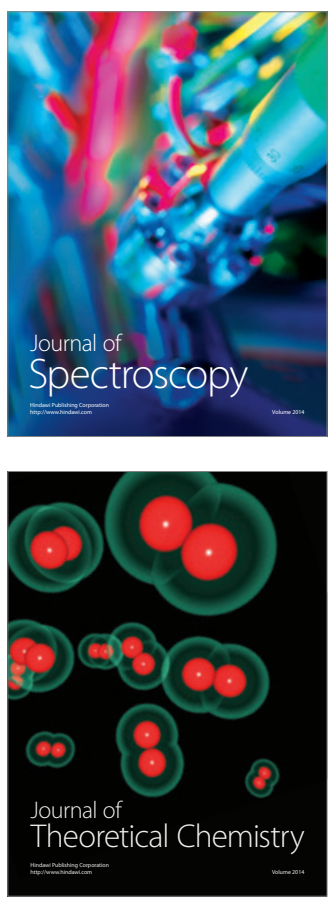
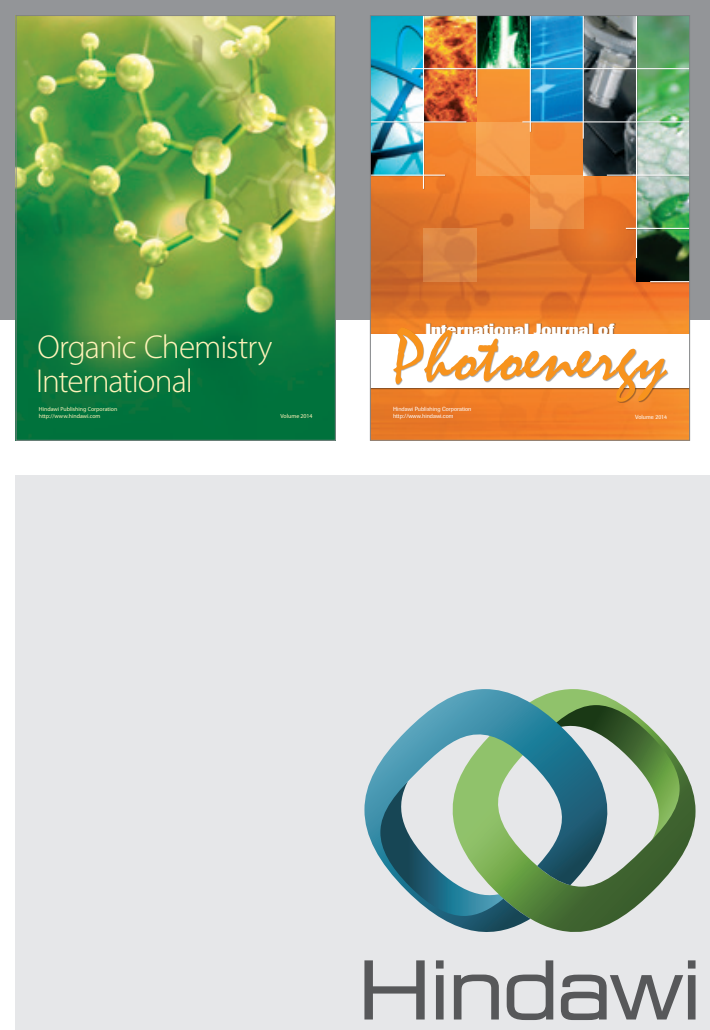

Submit your manuscripts at

http://www.hindawi.com
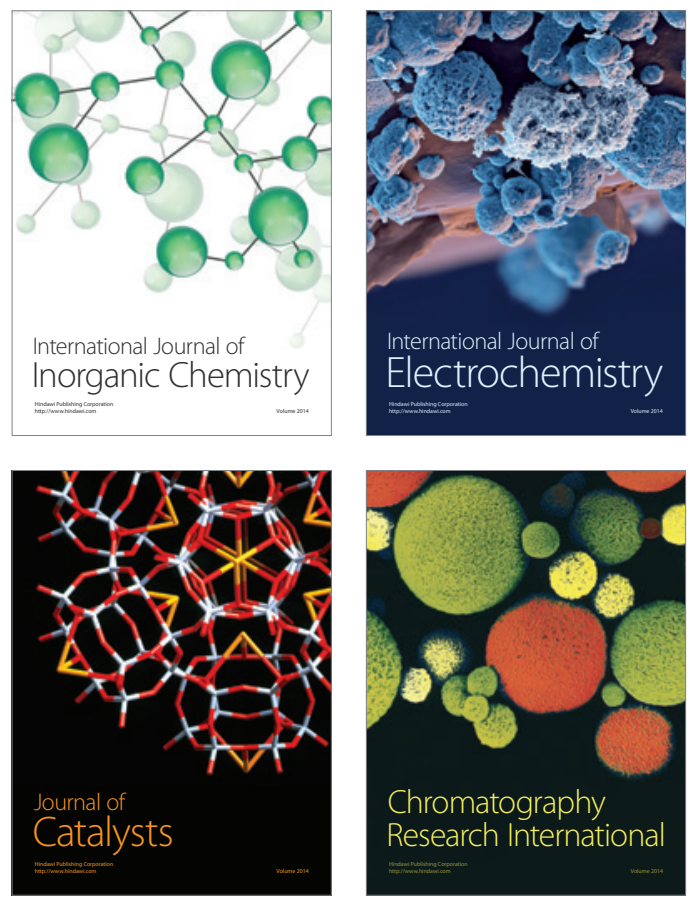
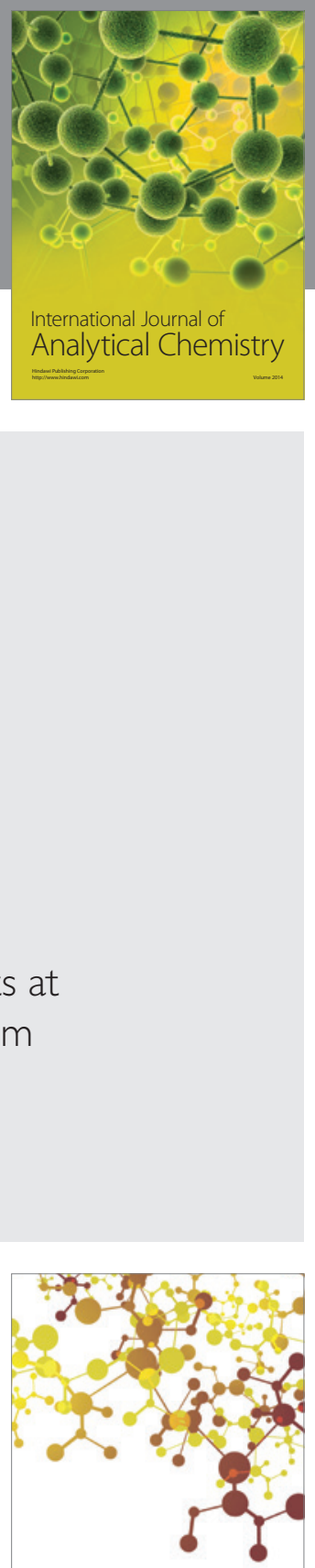

Journal of

Applied Chemistry
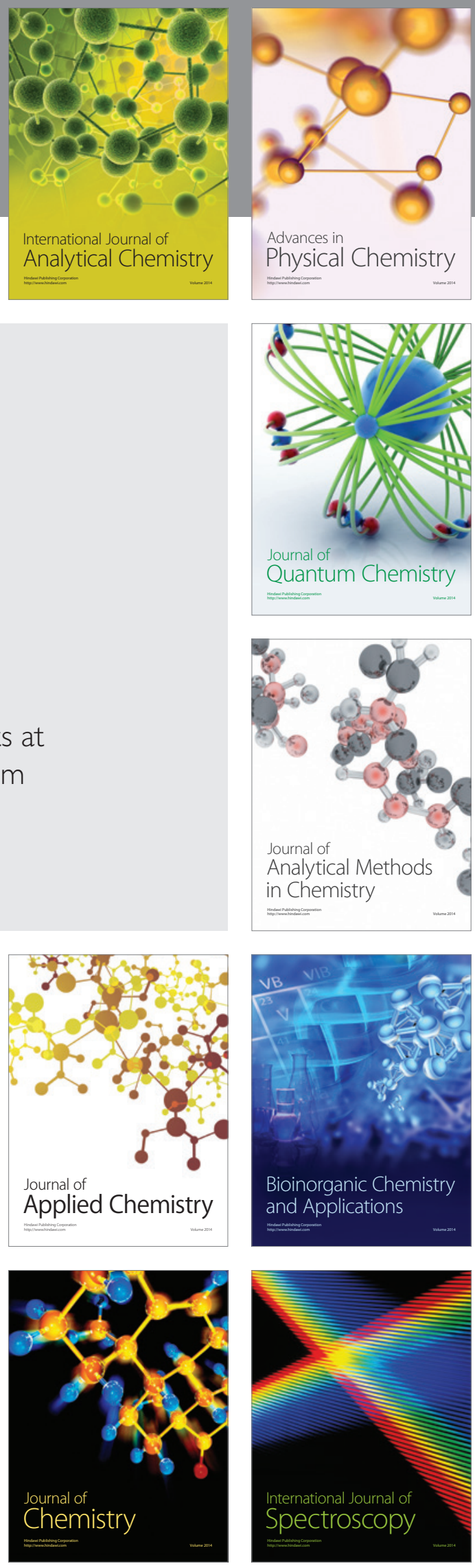